\title{
Fresh Water Struggle in Two Vietnam Regions
}

\section{Lo Kwong Fai Andrew* and Luu Thien Huong}

Graduate School of Earth Sciences, Chinese Culture University, Taipei, Taiwan

\begin{abstract}
Water is one of the most valuable natural resource, and most people are aware of the limited supply and importance of water. In Vietnam, public water systems have not been spread to all of the regions yet. Using surface water and groundwater remains the common solution for most residents. However, in some areas, surface water and groundwater is unsuitable for drinking purposes. Rainwater is considered to be a unique alternative for alleviating this problem. This study, therefore, aims at tackling the issues of the water supply encountered at two Vietnam regions, and to propose solutions not only to protect the environment and human livelihood but also for cutting down economic cost.
\end{abstract}

Keywords: Rainwater harvesting; Surface water; Groundwater; Salinity; Environmentally-friendly

\section{Introduction}

Vietnam has about 85 million inhabitants. According to the data of United Nations [1], from 1990 to 2004, the access to improved drinking water increased by $20 \%$ (from $65 \%$ to $85 \%$ ). Furthermore, from 1990 to 2004 , the access to improved sanitation increased by $25 \%$ (from $36 \%$ to $61 \%)$.

Vietnam is a tropical country with a long coastline. Because of the long stretch of the country's territory (Figure 1), Vietnam has a diversified culture and social background. Moreover, the complicated topography created multiform of climate and separated into three distinct regions including the North, the Central, and the South.

In the South and the North, two regions are chosen in this study that includes: Soc Trang Province in the South and $\mathrm{Cu}$ Khe Village in the North. Figure 1 shows the location of these two regions. Each region has a broad range of differences not only in climate condition but also in soil and water supply condition.

\section{Soc Trang Province}

Soc Trang is a coastal province in the Mekong Delta of Vietnam. It is about $231 \mathrm{~km}$ southwest of Ho Chi Minh City. Soc Trang is located in a tropical climate region, which is often influenced by monsoons. The season is divided into the dry season (from November to next year April), and the rainy season (from May to October). The average annual temperature of Soc Trang is about $26.8^{\circ} \mathrm{C}$, and the average annual rainfall is $1,864 \mathrm{~mm}$, concentrating in the August to November months.

\section{Cu Khe Village}

$\mathrm{Cu}$ Khe Village is located $15 \mathrm{~km}$ southwest of Hanoi (the capital city of Vietnam). $\mathrm{Cu}$ Khe is a well-known riverside ancient village. Abundant antique feature remains are the most unique characteristics of this northern village. This village covers an area of $5.76 \mathrm{~km}^{2}$ with nearly 5,000 inhabitants.

\section{Water Status in Soc Trang Province}

According to Herbst et al. [2], Soc Trang province has about 1.3 million inhabitants with over $75 \%$ living in rural areas without public water supply systems. Nearly $1 / 2$ of the residents in Soc Trang Province lack improved drinking water supply and $2 / 3$ lack improved sanitation.
Surface water: Due to the proximity of living habitat of the local people, they use surface water (river water) for the demands of daily activities such as bathing, laundry and washing dishes. The typical housing model in this area is garden-pond-livestock (Figure 2). Surface water is usually not fit for domestic use.

Ground water: In recent year, the intrusion of sea water in the Mekong Delta is at an alarming level. It has exerted great negative impact not only on the quality of the soil but also on the groundwater. The salinity of groundwater is becoming higher and not suitable for drinking purpose.

Bottled water: Bottled water comprises the highest quality drinking water. However, it is expensive compared to other sources. Therefore, bottled water is inadequate as a sustainable water supply.

Rainwater: Rainwater is the suitable choice for the local people. It is also the traditional water supply option in Soc Trang Province (Figure 3). The average annual rainfall in Soc Trang is about $1,864 \mathrm{~mm}$, which is much higher than the global average $(880 \mathrm{~mm})$. Facing with the current shortage of fresh water in this region, the efficient rainwater harvesting is extremely necessary.

\section{Water status in $\mathrm{Cu}$ Khe village}

$\mathrm{Cu}$-Khe Village is only about $15 \mathrm{~km}$ southwest of Hanoi City. However, it has no centralized water supply. An alternative safe water supply system is necessary. The villagers can obtain water from four different sources: surface water, ground water, bottled water, and rainwater.

Surface water: Due to the population growth and lack of infrastructure in Hanoi, large amounts of untreated domestic sewage have leaked into the nearby Nhue River. In addition, villagers often discharge their waste to the river. Eventually, the river ceased to function as a water supply option. It now resembles a huge sewer pool (Figure 4).

*Corresponding author: Lo Kwong Fai Andrew, Graduate School of Earth Sciences, Chinese Culture University, Taipei, Taiwan, Tel: 886-2-28617201; E-mail: andrewlo@faculty.pccu.edu.tw

Received July 02, 2015; Accepted July 16, 2015; Published July 22, 2015

Citation: Andrew LKF, Huong LT (2015) Fresh Water Struggle in Two Vietnam Regions. J Environ Anal Toxicol S7: 002. doi:10.4172/2161-0525.S7-003

Copyright: @ 2015 Andrew LKF, et al. This is an open-access article distributed under the terms of the Creative Commons Attribution License, which permits unrestricted use, distribution, and reproduction in any medium, provided the original author and source are credited. 


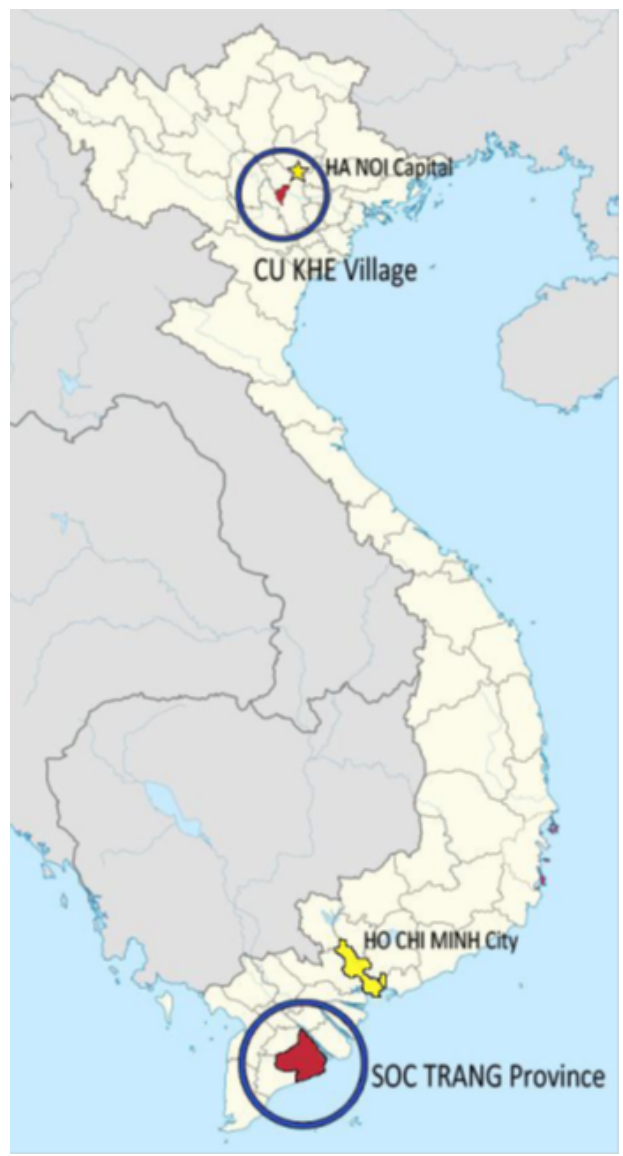

Figure 1: Location of Cu Khe Village and Soc Trang Province in Vietnam.

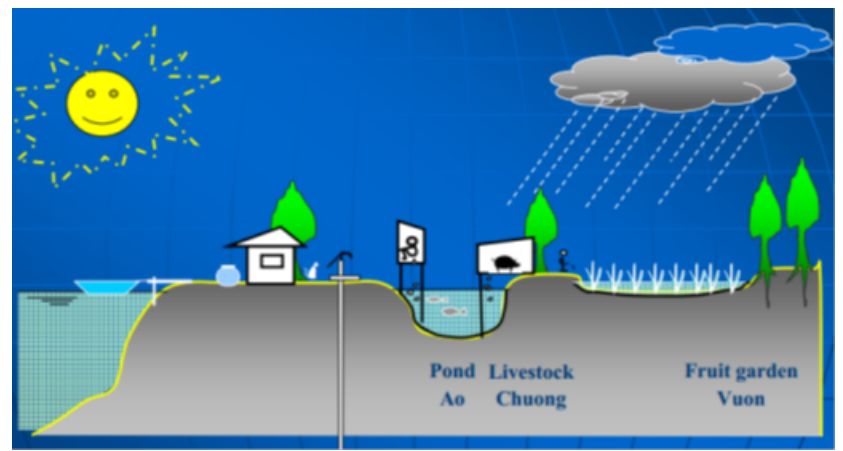

Figure 2: Typically housing model and sanitary situation in Soc Trang Province.

Groundwater: Groundwater is the most prevalent source of water in the rural area. However, groundwater has recently deemed undrinkable because of high concentrations of arsenic. Arsenic is classified as a class-one carcinogen that causes skin disease. According to the water analyzes conducted by the Vietnamese Government, the arsenic concentration in the ground water at most of the households in these villages exceeds the Vietnamese water quality standard of $0.05 \mathrm{mg} / \mathrm{L}$. The World Health Organization states that arsenic concentration standards should be below $0.01 \mathrm{mg} / \mathrm{L}$.

Bottled water: Bottled water comprises the highest quality drinking water in the village. However, it is expensive compared to other sources and supplying bottled drinking water for all family members are economically prohibitive. Therefore, bottled water is inadequate as a sustainable water supply.

Rainwater: Rainwater is the suitable choice for the local people. It is also the traditional water supply option in $\mathrm{Cu}$-Khe village. Because of the Southeast Asia monsoon climate, the average annual rainfall in this area is about $1,633 \mathrm{~mm}$. According to the study by Kim et al. [3], except for turbidity, the content levels of all the chemical substances tested satisfy the Vietnam water quality standards. Therefore, the main obstacle is to reduce turbidity to make rainwater more acceptable to users.

\section{A better solution}

The most feasible solution for both regions is to develop efficient methods to collect and filter rainwater to satisfy the demand of local people. In Figure 5, an improved method to collect rainwater is given.

To improve water quality, a sedimentation tank is added. A calminlet pipe is also installed to prevent settled particle disturbance and to minimize the kinetic energy of water flow for creating turbulence. A drain valve is added to the bottom of the tank to flush out precipitate. Aluminum is the most commonly used tank material in Vietnam. It has a hard surface so that settled particles are not easily disturbed. People can then obtain more clean water from this tank.

Table 1 shows the level of rainwater harvesting use in Vietnam, according to the study of Kim and Snelgrove [4-6]. The two study regions are highlighted. Obviously, utilization of rainwater harvesting is under-exploited. Immediate promotion and extension of rainwater harvesting systems by the public and private sectors is necessary to alleviate the fresh water supply problem in both regions.

\section{Conclusion}

With the widespread of drought and the damage of climate change, locating fresh and safe ground water is becoming more and more difficult. Using rainwater harvesting is a magical solution for these regions in Vietnam. Rainwater harvesting brings in a broad range of benefit such as lower utility bills, safe drinking water, flood reduction, erosion reduction, environmentally-friendly, and creating private-self reserve.

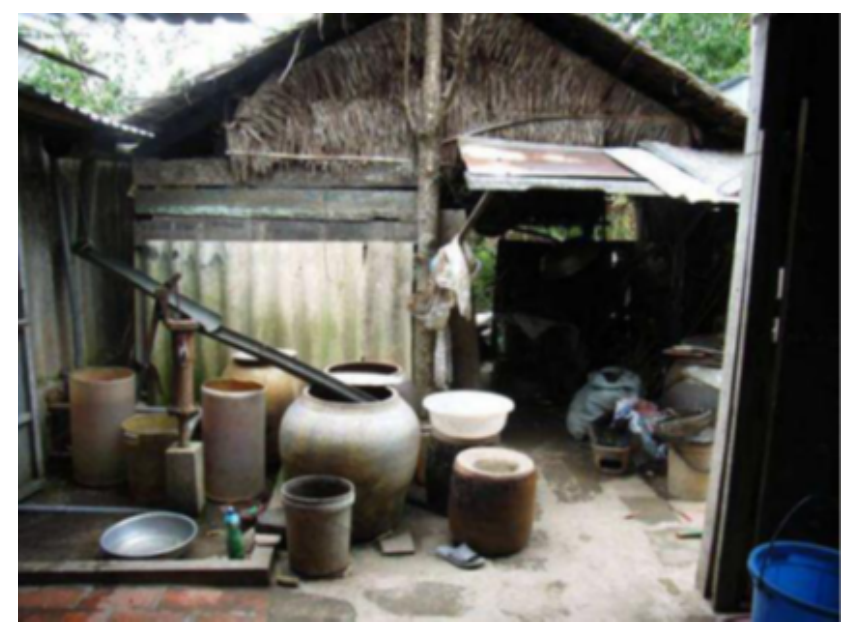

Figure 3: Typical rainwater harvesting system in Soc Trang Province 
Citation: Andrew LKF, Huong LT (2015) Fresh Water Struggle in Two Vietnam Regions. J Environ Anal Toxicol S7: 002. doi:10.4172/2161-0525. S7-003

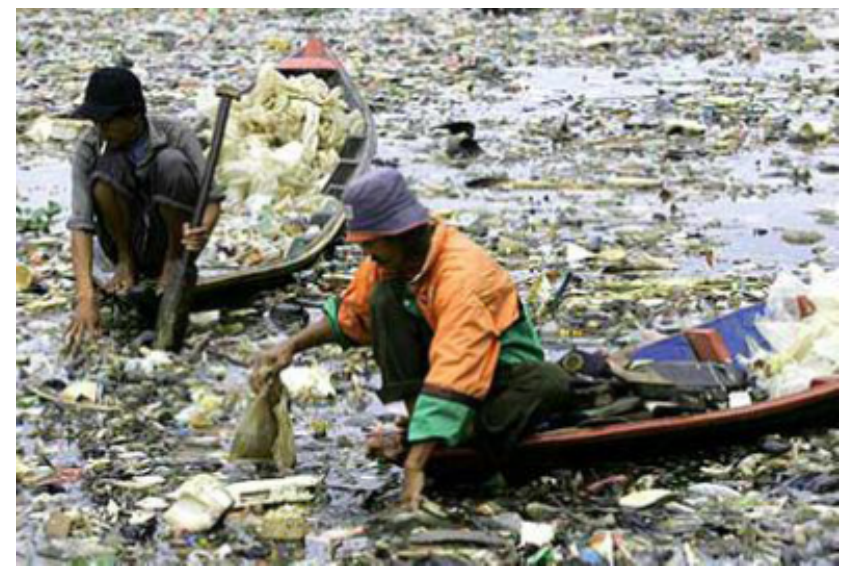

Figure 4: Water Pollution in the Nhue River, Cu Khe Village.

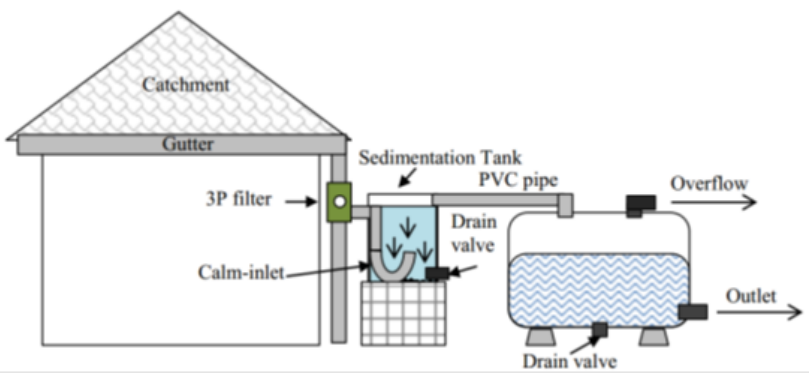

Figure 5: An improved rainwater harvesting system.

\begin{tabular}{|c|c|c|}
\hline Regions & $\begin{array}{c}\text { Vietnam Living } \\
\text { Standards Survey }\end{array}$ & $\begin{array}{c}\text { Vietnam National Health } \\
\text { Survey }\end{array}$ \\
\hline Red River Delta & 31.2 & 52.3 \\
\hline North East & 2.3 & 3.2 \\
\hline North West & 0.2 & 0.7 \\
\hline North Central & 4.1 & 9.6 \\
\hline Coast South Central & 0.1 & 0.2 \\
\hline Coast Central Highlands & 0.3 & 0.4 \\
\hline South East & 0.8 & 0.9 \\
\hline Mekong River Delta & 8.6 & 15.4 \\
\hline
\end{tabular}

Table 1: Level (in \%) of rainwater harvesting use in Vietnam.

\section{References}

1. United Nations (2006) The Millennium Development Goals Report 2006. United Nations Department of Economic and Social Affairs, New York.

2. Herbst S, Benedikter S, Koester U, Rechenburg A, Phan N, et al. (2008) Perception of water, sanitation, and health - a case study from the Mekong Delta, Vietnam. Water Sci Technol 60: 699-707.

3. Kim YH, Kum SY, Dzung DA, Han MY (2012) Analysis of rainwater using potential as water supply in a developing country - A case study of Laixa and Cukhe in Vietnam. IWA World Water Congress, Busan, South Korea 16-21.

4. Kim P, Snelgrove A (2009) Assessing the potential for rainwater harvesting in Vietnam. Rural Water Supply and Sanitation INGO Working Group Meeting.

5. Tuan LA (2003) Rural water supply manual. Can Tho University, Vietnam (in Vietnamese).

6. Özdemir S, Elliott M, Brown J, Pham NK, Thi HV, et al. (2011) Practices, preferences and attitudes for rainwater harvesting in Mekong Delta, Vietnam. Journal of Water, Sanitation and Hygiene for Development 1: 171-177.
This article was originally published in a special issue, Toxicology \& Environmental Safety handled by Editor(s). Dr. Abdel-Tawab H. Mossa, National Research Centre, Egypt 